\title{
PD-L1 expression with QR1 and E1L3N antibodies according to histological ovarian cancer subtype: A series of 232 cases
}

\author{
Caroline Eymerit-Morin, ${ }^{1}$ Anna Ilenko, ${ }^{2}$ Thomas Gaillard, ${ }^{2}$ Justine Varinot, ${ }^{1}$ Eva Compérat, ${ }^{1,3}$ \\ Sofiane Bendifallah, ${ }^{2,3,4}$ Emile Darai ${ }^{2,3,4}$
}

${ }^{1}$ Department of Anatomopathology, Tenon University Hospital, Assistance publique des Hopitaux de Paris (APHP.6), Sorbonne Université, Paris

${ }^{2}$ Gynecologic and Obstetrics Department, Tenon University Hospital, Assistance publique des Hôpitaux de Paris (APHP.6), Sorbonne Université, Paris

${ }^{3}$ UMR_S938, Sorbonne University, Hôpital Saint Antoine, Sorbonne Université, Paris

${ }^{4}$ Clinical Research Group (GRC6-Sorbonne Université) Endometriosis expert center, C3E, Paris, France

\begin{abstract}
Therapeutic strategies for epithelial ovarian cancers are evolving with the advent of immunotherapy, such as PD-L1 inhibitors, with encouraging results. However, little data are available on PDL-1 expression in ovarian cancers. Thus, we set out to determine the PD-L1 expression according to histological subtype. We evaluated the expression of two PD-L1 clones - QR1 and E1L3N - with two scores, one based on the percentage of labeled tumor cells (tumor proportion score, TPS) and the other on labeled immune cells (combined proportion score, CPS) in a consecutive retrospective series of 232 ovarian cancers. PD-L1 expression was more frequent in high grade serous carcinoma (27.5\% with E1L3N clone and $41.5 \%$ with QR1 clone), grade 3 endometrioid carcinoma (25\% with E1L3N clone and 50\% with QR1 clone), and clear-cell carcinomas (27.3\% with E1L3N clone and 29.6\% with QR1 clone) than other histological subtypes with CPS score. Using the CPS score, $17 \%$ of cases were labeled with E1L3N vs $28 \%$ with QR1. Using the TPS score, $14 \%$ of cases were positive to E1L3N vs 17\% for QR1. For TPS and CPS, respectively, 77\% and 78\% of the QR1 cases were concordant with E1L3N for the thresholds of $1 \%$. Overall and progression-free survival between PD-L1 positive and PD-L1 negative patients were not different across all histological types, and each subtype in particular for serous carcinomas expressing PD-L1. Expression of PD-L1 is relatively uncommon in epithelium ovarian tumors. When positive, usually $<10 \%$ of tumor cells are labeled. QR 1 clone and CPS appear the best tools to evaluate PD-L1 expression.
\end{abstract}

Key words: Ovarian cancer; PD-L1 antibody; immunochemistry; histological subtype.

Correspondence: Caroline Eymerit-Morin, Department of Anatomopathology, Tenon University Hospital, Assistance publique des Hopitaux de Paris (APHP.6), Sorbonne Université, 4 rue de la Chine, 75020 Paris, France. Tel. +33.1.56016677 - Fax:+33.1.56016676. E-mail: caroline.eymerit@aphp.fr

Contributions: CEM, reread the ovarian tumors and reclassified them according to the 2014 WHO classification if necessary, realized the micro-array tissue technique, the immunohistochemical analysis; AI, contributed of the inclusion of patients and the collection of clinical data, participated of TMA built and analyzed PD-L1 results; TG, carried out the statistical analyses, particularly the survival and disease-free survival curves; JV, was involved in the initial diagnosis of included tumors and participated in the blind double reading of the PD-L1 immunohistochemistry slides; EC, supervised and guided the work; SB, carried out the statistics between the clinical data and the expression of PD-L1; ED, supervised the work, reread and actively participated in the writing of the article. All the authors have read and approved the final version of the manuscript and agreed to be accountable for all aspects of the work.

Conflict of interest: The authors declare that they have no competing interests, and all authors confirm accuracy.

Availability of data and materials: The datasets used and/or analyzed during the current study are available from the corresponding author on reasonable request.0

Ethics approval: The study was approved by the Ethics Committee "Comité d'éthique de la recherche en Obstétrique et Gynécologie (CEROG)" (number CEROG 2019-GYN-1102 "phenotypic profiles identified in epithelial ovarian cancers").

Patient consent for publication: Not applicable. 


\section{Introduction}

Ovarian cancer (OC) is the seventh most frequent cancer diagnosed worldwide, with more than 240,000 new cases per year, and the eighth leading cause of cancer mortality with 152,000 deaths recorded in 2012. ${ }^{1}$ In France, OC is the fourth leading cause of cancer mortality in women with more than 3,100 deaths in 2017 (INCa). ${ }^{2}$ Recently, Coburn et al. evaluated the change in OC incidence worldwide showing an increase in Eastern/Southern Europe and Asia and a decrease in Northern Europe and North America. ${ }^{1}$.

Ovarian carcinomas include five major and distinct histological types with different characteristics and prognoses: high-grade serous carcinoma (HGSC, 70\%), low-grade serous carcinoma (LGSC, $<5 \%$ ), endometrioid carcinoma (EC, 10\%), clear-cell carcinoma (CCC, 10\%) and mucinous ovarian carcinoma (MOC, $3 \%) .{ }^{1}$ HGSC and CCC are of poorer prognoses. ${ }^{3,4}$ The Cancer Genome Atlas (TCGA) project identified genetic abnormalities or susceptibility alleles for the most common OCs and suggested several subtypes, including an immunoreactive subtype characterized by expression of the T-cell chemokine ligands more specifically identified in HGSC. ${ }^{5,6}$ Several studies have focused on inflammatory infiltrate, $\mathrm{T}$ cells and tumor-associated macrophage (TAM) expression on both OC cell lines and in vivo. ${ }^{7} \mathrm{PD} 1$ is implicated in programmed cell death and PD1/ PD-L1 is an important immune checkpoint in proliferation and development tumor. ${ }^{8}$ Tumor cells with PD-L1 transmembrane protein bind to the PD-1 receptor of T lymphocytes and inactivate them. ${ }^{8}$ Treatments that block the PD-1 receptor or the PD-L1 protein (anti-PD-1 or anti-PD-L1) can reverse the inactivation of $\mathrm{T}$ lymphocytes. These immune cells can subsequently have a tumor cell action. ${ }^{9}$ It has recently been suggested that the presence of intratumoral inflammatory infiltration associated with PD-L1 expression influences survival in $\mathrm{HGSC}^{10,11}$ with clinical trials using anti-PD-L1 immunotherapy such as pembrolizumab and avelumab showing promising results. ${ }^{6,12-15}$ Two recent meta-analysis suggested that PD-L1 expression was not linked to tumor histology, overall survival (OS), and progressionfree survival (PFS), but that PD-L1 mRNA expression was closely correlated with poor PFS. ${ }^{16,17}$ However, immunohistochemistry evaluation of PD-L1 before treatment was not always performed in these studies. Furthermore, in contrast to non-small-cell lung cancer, there is currently a lack of a consensual interpretation score for PD-L1 in OCs. Moreover, the published threshold of positivity is variable $^{18}$ giving rise to extensive debate about the prognostic and predictive values of response to treatment of PD-L1 expression. ${ }^{19,20}$ To date, there are no recommendations for evaluating immunohistochemical PD-L1 expression for targeted therapy in first line treatment of OCs (INCa). ${ }^{2}$

So far, no consensus exists on the best antibodies to use in ovarian cancer. Therefore, we decided to use the two PD-L1 antibodies (QR1 clone (Diagomics) and E1L3N (Cell Signaling)), that are consensual for other tumors such as lung cancer and routinely used. Therefore, the aims of this work were to evaluate PD-L1 expression with two antibodies and with two scores, in a large cohort of women with $\mathrm{OC}$ and to determine whether PD-L1 expression is correlated with clinicopathological features and prognosis.

\section{Materials and Methods}

\section{Patients/population}

The pathologic database of the Department of Pathology of Tenon University Hospital (Assistance Publique des Hôpitaux de
Paris, Sorbonne University Paris) was searched for all cases of histologically diagnosed OCs (including primary OCs with and without synchronous EC) from January 2005 to July 2017. All the patients had been treated at the ovarian cancer expert center in Tenon University Hospital. Exclusion criteria were tumor samples from other hospitals (cases sent for review) absence of formalin fixed and paraffin embedded (FFPE) tumor block in archives, no primary tissue tumor available, or absence or insufficient FFPE tumor material. Tissue samples were excluded after neoadjuvant chemotherapy. Borderline ovarian tumors were excluded. We recorded the clinicopathologic features, including histologic subtypes, tumor stage and grade, lymph node involvement, recurrence-free survival (RFS) and overall survival (OS) from the medical and pathologic reports. For each case, representative tumor tissue samples of the $\mathrm{OC}$ were used all of which had been routinely FFPE.

All the samples (whole slides) were reviewed by a gynecopathologist who reassessed the histologic diagnosis. FFPE blocks corresponding to primary $\mathrm{OC}$ were evaluated by routine hematoxylin and eosin (H\&E)-stained sections. One to three additional representative blocks were selected in case of contralateral OC.

Tumor stage was classified according to the International Federation of Gynecology and Obstetrics (FIGO 2014). If necessary, the histological type and stage have been reclassified taking into account the 2014 WHO classification. This has sometimes required additional immunohistochemical study, particularly in cases prior to 2010 .

\section{Tissue microarrays}

The tissue samples were used for the tissue microarrays (TMA). The arrays were constructed with a $1 \mathrm{~mm}$ punch on semi-automated Tissue Arrayer MiniCore ${ }^{\circledR} \quad\left(\right.$ Excilone $^{\circledR} \quad$ Alphelys $\left.^{\circledR}\right)$. Each selected/donor block was arrayed in triplicate including three tumor cores. The grid layout was designed using TMA designer software ${ }^{\circledR}$ and converted into a Microsoft Excel file. A $3 \mu \mathrm{m}$ H\&E-stained section was reviewed to confirm the presence of tumor sample. A histospot was considered unsuitable for analysis when it was completely absent, contained no tumor tissue (sampling error), or contained too few tumor cells for analysis (less than $10 \%$ of the surface area occupied by tumor cells was considered uninformative). Two cores with tumor cells were considered to be available for evaluation.

\section{Immunohistochemistry}

Immunohistochemistry (IHC) was performed on 5- $\mu$ m-thick whole tissue sections of TMA blocks in a Bond-III automated immunostainer (Leica Microsystems, Bannockburn, IL). We used two PD-L1 rabbit monoclonal antibodies: QR1 clone (Diagomics ${ }^{\circledR}$, Berlin, Germany ;1:100) and E1L3N clone (Cell signaling ${ }^{\circledR}$, , Leiden, Netherlands; $1: 100)$. The two antibodies were analyzed by the Ultraview Universal DAB Detection Kit (Roche Diagnostics ${ }^{\circledR}$ ). Beforehand, the protocol was finalized using appropriate positive and negative controls for each antibody according to the manufacturer's recommendations (tonsil tissue). Human tonsil tissue was used as a positive and negative control: positive lymphocyte cells and negative epithelial cells.

\section{IHC interpretation - TMA}

Two pathologists (CEM and JV) scored the PD-L1 staining independently. In the case of a discordant result between the two observers, the slides were reviewed in a dual-headed microscope and a consensus was established. Two scoring algorithms were used: the combined positive score (CPS) and the tumor proportion score (TPS). CPS is based on the number of PD-L1 stained cells (tumor 
cells, lymphocytes and macrophages) related to the number of tumor cells (in percentage). CPS $=$ PD-L1 positive cells (tumor cells+lymphocytes+macrophages)/ (tumors cells) x 100. Positive cells were defined by complete or incomplete circumferential membranous staining whatever the intensity. TPS is based on the percentage of positive tumor cells. TPS $=$ PD-L1 positive tumors cells /tumors cells x100. Tumor cell expression was considered positive when tumor cells showed complete or incomplete circumferential membranous staining whatever the intensity. All the fields of each TMA spot were analyzed at low magnification. We counted the number of labelled and unlabeled tumor cells and labelled immune cells on 10 fields (high power magnification, $\mathrm{x} 400$ ), in the areas most represented in tumor cells. We established an average for each tumor analyzed for CPS and TPS Score.

\section{Statistical analysis}

Concordance of IHC expression between the two antibodies

Table 1. Epidemiologic and histologic characteristics of the population.

\begin{tabular}{|c|c|c|}
\hline Variable & & Patients (percentage) \\
\hline Median age at diagnosis (year) & 56.32 & $\pm 13 \mathrm{SD}$ \\
\hline $\begin{array}{l}\text { Hormonal status } \\
\text { Menopausal } \\
\text { Non menopausal } \\
\end{array}$ & & $\begin{array}{c}118(63.6 \%) \\
53(28.8 \%)\end{array}$ \\
\hline $\begin{array}{l}\text { Body mass index }\left(\mathrm{kg} / \mathrm{m}^{2}\right) \\
\text { BRCA mutation } \\
\text { Absent } \\
\text { Present }\end{array}$ & & $\begin{array}{c}19.6 \pm 4.1 \\
88(47.8 \%) \\
22(12 \%)\end{array}$ \\
\hline $\begin{array}{l}\text { FIGO stage } \\
\text { I } \\
\text { II } \\
\text { III } \\
\text { IV }\end{array}$ & & $\begin{array}{l}45(22.9 \%) \\
25(14.4 \%) \\
92(52.9 \%) \\
12(6.9 \%)\end{array}$ \\
\hline
\end{tabular}

Table 2. Distribution of histologic subtype of the 184 patients with ovarian tumors.

\begin{tabular}{lc} 
Histologic subtype & $\begin{array}{c}\text { Number of cases (\%) } \\
\text { (total n=184) }\end{array}$ \\
Serous carcinoma & $93(50.5 \%)$ \\
Low grade & 16 \\
High grade & 77 \\
Endometrioid carcinoma & $37(20.1 \%)$ \\
Grade G1 & 12 \\
Grade G2 & 12 \\
Grade G3 & 13 \\
\hline Clear cell carcinoma & $25(13.6 \%)$ \\
Mucinous carcinoma & $12(6.5 \%)$ \\
Expansive type & 4 \\
Seromucinous carcinoma & $6(3.3 \%)$ \\
\hline Carcinosarcoma & $4(2.2 \%)$ \\
Malignant Brenner tumor & $1(0.5 \%)$ \\
Sex cord and stroma tumor & $6(3.3 \%)$ \\
Or germ cell tumor & \\
Immature teratoma & 1 \\
Granulosa tumor & 3 \\
Sertoli-Leydig tumor & 1 \\
Embryonal carcinoma & 1 \\
\hline
\end{tabular}

was expressed as a kappa statistic. Kappa statistics measures the agreement between two observers (interobserver). ${ }^{21} \mathrm{~A}$ kappa value of 1 indicates perfect concordance, 0 means agreement at the level of chance, and negative values agreement worse than chance agreement. A kappa value of 0 to $0.2,0.21$ to $0.4,0.41$ to $0.6,0.61$ to 0.8 , and 0.81 to 1 was considered slight, fair, moderate, substantial, and almost perfect agreement, respectively. OS and RFS were estimated from log-rank test, Kaplan-Meier curves and, cumulative-incidence methods. A p-value of 0.05 was considered to denote significance. All statistical analysis was performed on Review Manager (RevMan, IOS, version (5.3).

\section{Results}

\section{Characteristics of the study population}

Between 2005 and 2017, of the 184 patients with OC included in the database, 48 had bilateral OC. Among them, 13 patients had synchronous or metachronous uterine carcinoma. Forty-four tissue samples were excluded after neoadjuvant chemotherapy. Therefore, the study population included 232 ovarian tumors. After review and addi-

Table 3. Distribution of PD-L1 expression in ovarian cancer using E1L3N antibody and QR1 antibody according to CPS and TPS scores.

\begin{tabular}{|c|c|c|c|c|}
\hline \multirow[t]{2}{*}{$\begin{array}{l}\text { Score } \\
\text { (TPS or CPS) }\end{array}$} & \multicolumn{2}{|c|}{$\begin{array}{c}\text { E1L3N antibody } \\
\text { number } \\
\text { of cases }\end{array}$} & \multicolumn{2}{|c|}{$\begin{array}{l}\text { QR1 antibody } \\
\text { number } \\
\text { of cases }\end{array}$} \\
\hline & TPS & CPS & TPS & CPS \\
\hline 0 (negative) & 148 & 142 & 181 & 155 \\
\hline 0.5 & 9 & 7 & 22 & 37 \\
\hline 1 & 12 & 8 & 7 & 3 \\
\hline 2 & 3 & 10 & 1 & 9 \\
\hline 3 & 0 & 2 & 0 & 4 \\
\hline 5 & 1 & 2 & 3 & 3 \\
\hline 7 & 0 & 0 & 1 & 2 \\
\hline 8 & 1 & 0 & 0 & 0 \\
\hline 10 & 2 & 3 & 0 & 2 \\
\hline 15 & 2 & 2 & 3 & 0 \\
\hline 17 & & 1 & 0 & 0 \\
\hline 20 & 1 & 0 & 0 & 2 \\
\hline 25 & 0 & 1 & 0 & 1 \\
\hline 30 & 0 & 0 & 1 & 0 \\
\hline 38 & 0 & 0 & 0 & 1 \\
\hline 40 & 0 & 1 & 0 & 0 \\
\hline 50 & 0 & 0 & 1 & 0 \\
\hline 60 & 0 & 0 & 0 & 1 \\
\hline 80 & 2 & 0 & 0 & 0 \\
\hline 85 & 0 & 1 & 0 & 0 \\
\hline 100 & 0 & 1 & 0 & 0 \\
\hline NR & 51 & 51 & 12 & 12 \\
\hline Total & 232 & & & \\
\hline
\end{tabular}

TPS, tumor proportion score $=$ PD-L1 positive tumors cells /tumors cells x100; CPS, combined proportion score $=$ PD-L1+ cells (tumor cells + lymphocytes + macrophages) $/$ (tumors cells) $\mathrm{x}$ 100 ; NR, not representative. 
tional immunohistochemical study, 23 mixed carcinomas diagnosed before 2014 were reclassified mainly as high-grade serous carcinoma and seromucinous carcinoma according to 2014 WHO classification. Clinical and histological parameters are summarized in Tables 1 and 2. The most common histologic subtypes were serous carcinomas $(50.5 \%)$ including $82.8 \%$ of high-grade serous carcinoma (HGSC) and $17.2 \%$ of low-grade serous carcinoma (LGSC). EC was the second most common subtype (20.1\%). CCCs were diagnosed in $13.6 \%$ of patients. Finally, sex cord stroma tumor (SCST) and germ cell tumor (GCT) constituted $3.3 \%$ of patients.

\section{Qualitative expression of PD-L1 using E1L3N and QR1 antibodies}

PD-L1 labeling was mostly weak overall. PD-L1 expression was represented as both complete and incomplete circumferential membranous staining of tumor cells as shown in Figure 1. Labeling was absent for $64 \%$ of cases with E1L3N and $78 \%$ with QR1 (Figure 1 E,F). A few cases (14\% with E1L3N and 17\% with QR1) showed expression of PD-L1 with the two antibodies (Figure $1 \mathrm{~B}, \mathrm{C}, \mathrm{G}, \mathrm{H})$. PD-L1 expression was not evaluable in $22 \%$ of cases with E3L1N and in 5\% of cases with QR1. Immune cells were scarce and rarely labeled (Figure 1C) with no difference for the two antibodies. Interobserver agreement test for qualitative PD-L1 expression was substantial $($ Kappa $=0.77)$ for both E1L3N and QR1 antibodies. Interobserver discrepancies corresponded mainly to equivocal cases $(6 \%)$.

\section{Immunochemistry expression of PD-L1 according to antibodies and histologic subtypes}

Distributions of PD-L1 expression according to TPS and CPS with the E1L3N antibody are presented in Table 3.

\section{TPS of PD-L1 expression using the E1L3N antibody}

IHC study was inconclusive with the E1L3N antibody in $22 \%$ of the OC samples. TPS was negative in $64 \%$ of the cases $(148 / 232)$ and positive in $14 \%$ (33/232). Of the positive cases, the staining was mainly weak concerning less than $10 \%$ of tumor cells (Table 4). TPS with 10\%-50\% of labeled cells was observed in five cases $(2 \%)$. TPS with more than $50 \%$ of labeled cells was observed in only two tumors ( $1 \%$ of cases).

\section{CPS of PD-L1 expression using the E1L3N antibody}

CPS was negative in $61 \%$ of cases (142/232) and positive in 17 $\%(39 / 232)$. The staining was mainly weak concerning less than $10 \%$ of tumor cells in $13 \%$ (Table 4 ). CPS with $10 \%-50 \%$ of labeled cells was observed in eight cases $(3 \%)$ while cases with
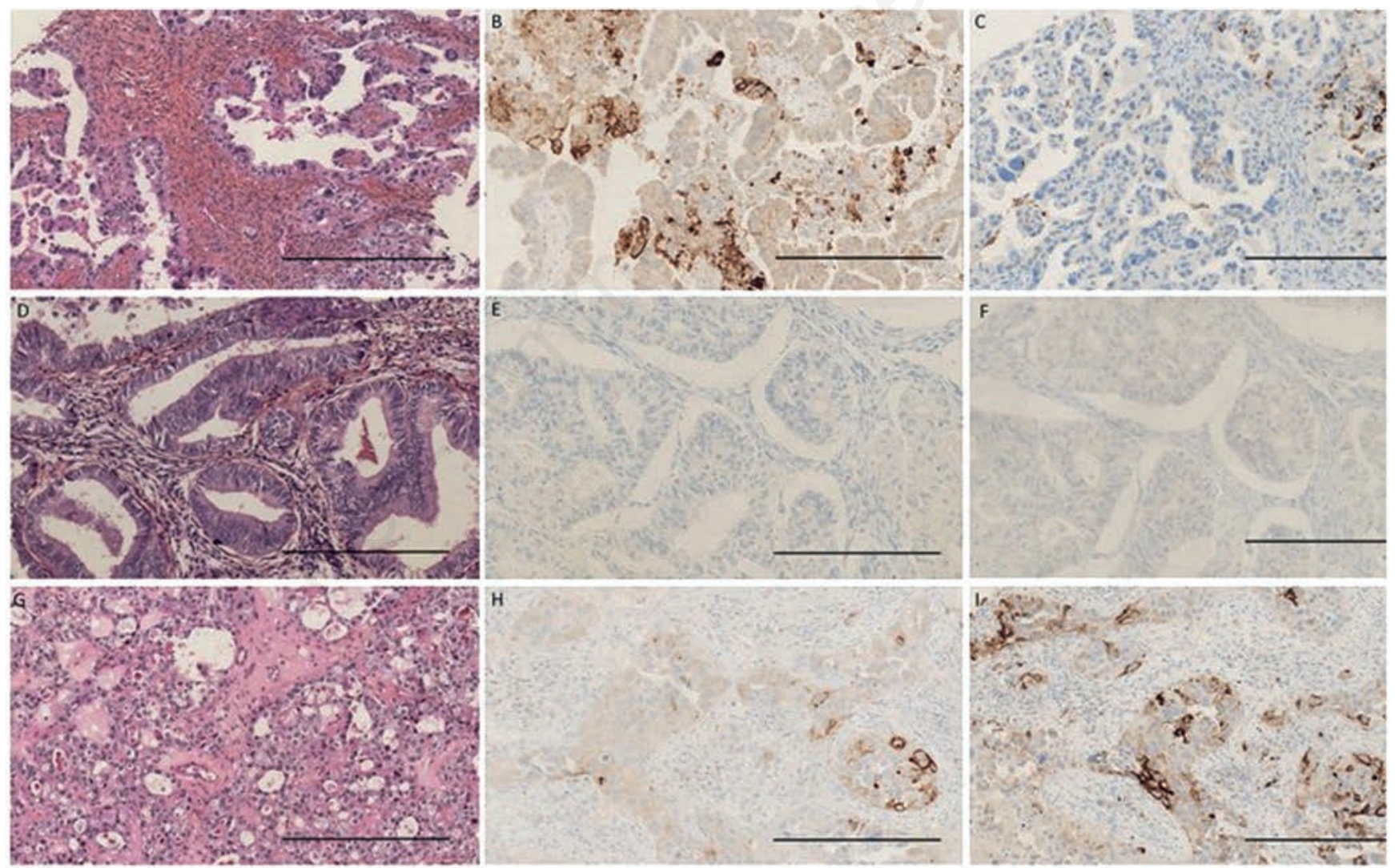

H
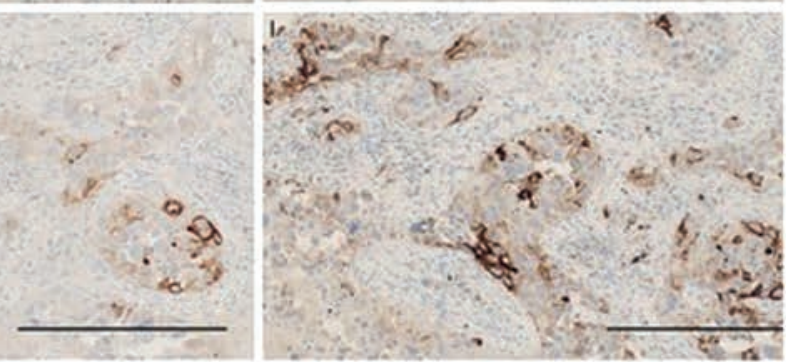

Figure 1. Immunohistochemical expression of PD-L1 in ovarian carcinomas. The tumors examined show very low peri- or intratumoral inflammatory infiltration. This may explain why the CPS score is lower compared with the TPS score, related to the low proportion of immune cells present in these tumors. A-C) High Grade Serous Carcinoma, magnification x 200. A) Hematoxylin Eosin staining; B) expression of E1L3N: strong and heterogeneous membrane staining of $>10 \%$ cells (TPS $=15, \mathrm{CPS}=25)$; C) expression of QR1: focal and rare membrane staining of $<10 \%$ cells including a majority of immune cells (TPS = 5; CPS $=7$ ). D-F) Grade 2 Endometrioid carcinoma, magnification x200. D) Hematoxylin \& Eosin staining; E) lack of expression of E1L3N; F) lack of expression of QR1(TPS = 0, CPS = 0). G-I) Clear cell carcinoma, magnification x 200; G) Hematoxylin \& Eosin staining; H) expression of E1L3N <10\% tumor cells $(\mathrm{TPS}=8$; CPS $=10$ ); $\mathrm{I}$ ) expression of $\mathrm{QR1} \geq 50 \%$ tumors cells $(\mathrm{TPS}=30$; CPS=38). Interpretation is easy in the majority of cases with the two antibodies used as shown in these pictures. Scale bars: $250 \mathrm{~m}$. 
CPS over $50 \%$ were observed in two tumors ( $1 \%$ of cases). An excellent correlation was noted between TPS and CPS (Kappa=0.89).

\section{TPS and CPS of PD-L1 expression using the E1L3N antibody according to histologic subtypes}

A variation in $\mathrm{PD}-\mathrm{L} 1$ expression was observed according to histologic subtypes independently of the IHC score used. Using TPS, $27.3 \%$ of CCCs expressed PD-L1, $22 \%$ of SCs, $14.3 \%$ of ECs and $14.3 \%$ of seromucinous carcinomas. TPS was absent in MOCs (Table 5). Using CPS, 27.3\% of CCCs expressed PD-L1, $23 \%$ of SCs, $20 \%$ of ECs, and $14.3 \%$ of seromucinous carcinomas. CPS was also negative in MOCs. Two of the five carcinosarcomas expressed PD-L1 with TPS or CPS score (Table 5). HGSC expressed significantly more PD-L1 than LGSC (27.5\% vs 5\% with CPS score and $22.5 \%$ vs $5 \%$ with TPS score). G2 or G3 grade EC also expressed more PD-L1 than G1 grade endometrioid carcinomas ( $25 \%$ vs $13.3 \%$ with CPS score and $27.3 \%$ vs $12.5 \%)$.

\section{TPS and CPS of PD-L1 expression using the QR1 anti- body}

Distributions of PD-L1 expression according to TPS and CPS with the QRI antibody are presented in Tables 3 and Table 5.

\section{TPS of PD-L1 expression using the QRI antibody}

IHC study was inconclusive with the QR1 antibody in 5.2\% of cases. TPS was negative in $78 \%$ of the cases (181/232) and positive in $17 \%(39 / 232)$. Of the positive cases, the staining was mainly weak concerning less than $10 \%$ of tumor cells in $15 \%$ (Table 2 ). The staining was mainly weak (Table 5 ). TPS with $10 \%-50 \%$ of labeled cells was observed in four cases (2\%). TPS with more than $50 \%$ of labeled cells was observed in one tumor ( $1 \%$ of cases).

\section{CPS of PD-L1 expression using the QRI antibody}

CPS was negative in $67 \%$ of the cases $(155 / 232)$ and positive in $28 \%(65 / 232)$. Of the positive cases, the staining was mainly weak concerning less than $10 \%$ of tumor cells in $25 \%$ (Table 2 ). CPS with $10 \%-50 \%$ of labeled cells was observed in 6 cases $(3 \%)$ while only one case showed a staining of more than $50 \%$ of the tumor cells.

\section{TPS and CPS of PD-L1 expression using the QR1 anti- body according to histologic subtypes}

As for the E1L3N antibody, a variation in QR1 expression was observed according to histologic subtypes for both scores. Using the TPS score, $18.5 \%$ of CCCs expressed QR1, 22.4\% of SCs, $13.35 \%$ of ECs, and $8.3 \%$ of MCs (1/12) (Table 5. Four cases
(4/27; 15\%) of CCCs had TPS score ${ }^{3} 10 \%$. With the CPS score, $29.6 \%$ of CCCs expressed QR1, 37.9\% of SCs, $22.2 \%$ of ECs, $8.3 \%$ of MOCs $(1 / 12)$.

TPS and CPS were negative in carcinosarcomas and seromucinous carcinomas (Table 5). HGSC expressed significantly more PD-L1 than LGSC (41.5\% vs $22.7 \%$ with CPS score and $24.5 \%$ vs $13.6 \%$ with TPS score). G2 or G3 grade EC also expressed more PD-L1 than G1 grade endometrioid carcinomas ( $50 \%$ vs $13.3 \%$ with CPS score and $31.3 \%$ vs $6.7 \%$ ).In tumors with a CPS over $10 \%, 2.2 \%$ of ECs were positive for PD-L1 (1/45), $1.7 \%$ of SCs (2/116) and $15.4 \%$ of CCCs (4/27). The proportion of tissue samples not evaluable for either TPS or CPS was significantly lower for the QR1 than the E1L3N antibody (Table 5). For TPS, the percentage of tumors labeled was similar for both QR1 and E1L3N antibodies taking into account the number of available cases (respectively $17.7 \%$ vs $18.2 \%$ ). For CPS, a higher proportion of tumors was labeled using QR1 (29.5\% vs 21.5\%) than for E1L3N antibody ( $\mathrm{p}=0.0029)$.

\section{Disease free survival, overall survival and PDL1 expression}

There was no difference in OS between patients expressing PD-L1 $(n=43)$ and those with no PD-L1 expression $(n=85)$; $(\mathrm{p}=0.16$; Figure 2$)$.

In the whole population, no difference in DFS was found according to the PD-L1 status ( $\mathrm{p}=0.25$; Figure 3 ).

Three-year OS was $81.8 \%$ vs $81.8 \%$, for PD-L1- and PD-L1+ patients, respectively. Five-year OS was $62 \%$ vs $74 \%$, for PD-L1and PD-L1+ patients, respectively. No difference in OS or DFS was noted according to histologic subtype (Figure 3).

\section{Discussion}

The present study demonstrates that a relatively low percentage of OCs express PD-L1 with variations according to histological subtypes. Moreover, the QR1 antibody is associated with a lower rate of non-evaluable tissue samples compared to E1LN3. Finally, CPS appears to be more sensitive than TPS to detect PDL1 positive tumors.

Using qualitative evaluation of PD-L1, from two-thirds to three-quarters of samples were negative with no difference between the two antibodies. Using semi-quantitative evaluation of PD-L1, the proportion of tissue samples not evaluable was significantly lower when using the QR1 compared with the E1L3N antibody. Moreover, TPS gave a similar percentage of labeled tumors

Table 4. Semi-quantitative distribution of PD-L1 expression in ovarian cancer using E1L3N and QR1 antibodies according to CPS and TPS scores.

\begin{tabular}{|c|c|c|c|c|c|c|c|c|}
\hline \multirow{2}{*}{$\begin{array}{l}\text { Score } \\
\text { TPS or CPS }\end{array}$} & \multirow[b]{2}{*}{ TPS (n) } & \multicolumn{3}{|c|}{$\begin{array}{l}\text { E1L3N antibody } \\
\text { Number of cases }\end{array}$} & \multirow[b]{2}{*}{ TPS (n) } & \multicolumn{2}{|c|}{$\begin{array}{l}\text { QR1 antibody } \\
\text { Number of cases }\end{array}$} & \multirow[b]{2}{*}{$(\%)$} \\
\hline & & $(\%)$ & CPS (n) & $(\%)$ & & $(\%)$ & CPS (n) & \\
\hline 0 & 148 & $64 \%$ & 142 & $61 \%$ & 181 & 78\% & 155 & $67 \%$ \\
\hline $0-10$ & 26 & $11 \%$ & 29 & $13 \%$ & 34 & $15 \%$ & 58 & $25 \%$ \\
\hline $10-50$ & 5 & $2 \%$ & 8 & $3 \%$ & 4 & $2 \%$ & 6 & $3 \%$ \\
\hline $50-100$ & 2 & $1 \%$ & 2 & $1 \%$ & 1 & $0 \%$ & 1 & $0 \%$ \\
\hline NR & 51 & $22 \%$ & 51 & $22 \%$ & 12 & $5 \%$ & 12 & $5 \%$ \\
\hline Total & 232 & & & & & & & \\
\hline
\end{tabular}

TPS, tumor proportion score = PD-L1 positive tumors cells /tumors cells x100; CPS, combined proportion score = PD-L1+ cells (tumor cells + lymphocytes+ macrophages)/(tumors cells) x 100; NR, not representative. 
for the two antibodies while CPS gave a higher proportion of tumors labeled by the QR1 antibody $(\mathrm{p}=0.0029)$. This suggests that PD-L1 expression in OC is more accurately evaluated with the QR1 antibody and the CPS score. However, specimens expressing PD-L1 in more than $10 \%$ of tumor cells were significantly higher with the E1LN3 clone suggesting greater sensitivity. When considering PD-L1 expression according to OC histological subtypes, we found a relatively high expression in HGSCs followed by CCCs and G3 ECs. The comparison of our data with those of previous studies is difficult as other studies mainly focus on one OC histological subtype. Wanq et al. confirmed that PD-L1 expression in HGSC was uncommon and often focal in $24.3 \%$ of cases $(26 / 81)$ using a $5 \%$ threshold of labeled tumor cells (TPS score). ${ }^{10}$ They showed a significant association between PD-L1 and CD8+ tumor infiltrating lymphocyte expression. ${ }^{10}$ Another study showed PD-L1 expression in $23.6 \%$ of HGSC cases $(55 / 233)$ with a $1 \%$ threshold of labeled tumor cells. ${ }^{22}$ Schmoeckel et al.'s study involving 288 OCs showed PD-L1 expression ( $>1 \%$ of tumor cells) in $19.5 \%$ (55 HGSC and two EC). ${ }^{22}$

Besides the low expression of PD-L1 in OC, another issue is the absence of consensus about how to evaluate PD-L1 expression and the definition of a positive threshold. Several studies use a threshold of $5 \%$ while others choose $1 \%$ as in pulmonary pathology. ${ }^{23-26}$ Some studies use a semi-quantitative evaluation reporting a percentage of positive cells, ${ }^{24}$ while others only report the staining of tumor cells, or both tumor and inflammatory cells staining in stroma. ${ }^{25,26} \mathrm{~A}$ meta-analysis showed a wide variation $(11 \%$ to $88 \%)$ in the proportion of ovarian tumors expressing PDL1. ${ }^{2}$ These apparent variations could be explained by differences according to the histological subtypes, the scoring method, and the

Table 5. Antibodies E1L3N and QR1 cell signaling; score according to histological subtype.

\begin{tabular}{|c|c|c|c|c|c|c|c|c|c|}
\hline \multirow[t]{2}{*}{ E1L3N antibody } & \multicolumn{4}{|c|}{ CPS immunoscore } & \multirow[t]{2}{*}{ NR } & \multicolumn{4}{|c|}{ TPS score (\%) } \\
\hline & 0 & $0-10$ & $10-50$ & $50-100$ & & 0 & $0-10$ & $10-50$ & $50-100$ \\
\hline Serous carcinoma & 77 & 16 & 6 & 1 & & 81 & 15 & 3 & 1 \\
\hline High grade serous carcinoma & 58 & 15 & 6 & 1 & 19 & 62 & 14 & 3 & 1 \\
\hline Low grade serous carcinoma & 19 & 1 & & & 3 & 19 & 1 & & \\
\hline $\begin{array}{l}\text { Endometrioid carcinoma } \\
\text { Grade G1 } \\
\text { Grade G2 } \\
\text { Grade G3 }\end{array}$ & $\begin{array}{l}28 \\
13 \\
6 \\
9\end{array}$ & $\begin{array}{l}7 \\
2 \\
2 \\
3\end{array}$ & & & $\begin{array}{l}1 \\
6 \\
5\end{array}$ & $\begin{array}{c}30 \\
14 \\
7 \\
9\end{array}$ & $\begin{array}{l}5 \\
1 \\
1 \\
3\end{array}$ & & \\
\hline Clear cell carcinoma & 16 & 3 & 2 & 1 & 5 & 16 & 3 & 2 & 1 \\
\hline Mucinous carcinoma & 9 & & & & 5 & 9 & & & \\
\hline Seromucinous carcinoma & 6 & 1 & & & 1 & 6 & 1 & & \\
\hline Carcinosarcoma & 3 & 2 & & & 2 & 3 & 2 & & \\
\hline Malignant Brenner tumor & 1 & & & & & 1 & & & \\
\hline $\begin{array}{l}\text { SCST or GCT } \\
\text { Granulosa } \\
\text { Immature teratoma } \\
\text { Embryonal carcinoma } \\
\text { Sertoli-Leydig tumor }\end{array}$ & $\begin{array}{l}2 \\
2\end{array}$ & & & & $\begin{array}{l}1 \\
1 \\
1 \\
1\end{array}$ & $\begin{array}{l}2 \\
2\end{array}$ & & & \\
\hline Total & $\begin{array}{l}142 \\
61 \%\end{array}$ & $\begin{array}{c}29 \\
13 \%\end{array}$ & $\begin{array}{c}8 \\
3 \%\end{array}$ & $\begin{array}{c}2 \\
1 \%\end{array}$ & $\begin{array}{c}51 \\
22 \%\end{array}$ & $\begin{array}{c}148 \\
64 \%\end{array}$ & $\begin{array}{c}26 \\
11 \%\end{array}$ & $\begin{array}{c}5 \\
2 \%\end{array}$ & $\begin{array}{c}2 \\
1 \%\end{array}$ \\
\hline QR1 antibody & 0 & $0-10$ & $10-50$ & $50-100$ & NR & 0 & $0-10$ & $10-50$ & $50-100$ \\
\hline Serous carcinoma & 72 & 42 & 1 & 1 & & 90 & 25 & & 1 \\
\hline High grade serous carcinoma & 55 & 37 & 1 & 1 & 5 & 71 & 22 & & 1 \\
\hline Low grade serous carcinoma & 17 & 5 & & & 1 & 19 & 3 & & \\
\hline $\begin{array}{l}\text { Endometrioid carcinoma } \\
\text { Grade G1 } \\
\text { Grade G2 } \\
\text { Grade G3 }\end{array}$ & $\begin{array}{l}35 \\
13 \\
14 \\
8\end{array}$ & $\begin{array}{l}9 \\
2 \\
7\end{array}$ & 1 & & $\begin{array}{l}1 \\
1\end{array}$ & $\begin{array}{l}39 \\
14 \\
14 \\
11\end{array}$ & $\begin{array}{l}6 \\
1 \\
5\end{array}$ & & \\
\hline Clear cell carcinoma & 19 & 4 & 4 & 0 & & 22 & 1 & 4 & 0 \\
\hline Mucinous carcinoma & 11 & 1 & & & 2 & 11 & 1 & & \\
\hline Seromucinous carcinoma & 8 & & & & & 8 & & & \\
\hline Carcinosarcoma & 5 & 0 & & & 2 & 5 & 0 & & \\
\hline Malignant Brenner Tumor & 1 & & & & & 1 & & & \\
\hline $\begin{array}{l}\text { SCST ot GCT } \\
\text { Granulosa } \\
\text { Immature teratoma } \\
\text { Embryonar carcinoma } \\
\text { Sertoli-Leydig tumor }\end{array}$ & $\begin{array}{l}4 \\
2 \\
1 \\
1\end{array}$ & $\begin{array}{l}2 \\
1\end{array}$ & & & & $\begin{array}{l}5 \\
2 \\
1 \\
1 \\
1\end{array}$ & $\begin{array}{l}1 \\
1\end{array}$ & & \\
\hline Total & $\begin{array}{l}155 \\
67 \% \\
\end{array}$ & $\begin{array}{r}58 \\
25 \% \\
\end{array}$ & $\begin{array}{c}6 \\
3 \% \\
\end{array}$ & $\begin{array}{c}1 \\
0 \% \\
\end{array}$ & $\begin{array}{c}12 \\
5 \% \\
\end{array}$ & $\begin{array}{l}181 \\
78 \% \\
\end{array}$ & $\begin{array}{c}34 \\
15 \% \\
\end{array}$ & $\begin{array}{c}4 \\
2 \% \\
\end{array}$ & $\begin{array}{c}1 \\
0 \% \\
\end{array}$ \\
\hline
\end{tabular}


antibodies used. In the current study, two quantitative scores were used as for lung, head and neck pathologies. PD-L1 expression is well documented (sensitivity, specificity) and used in routine practice in lung pathologies ${ }^{27}$ and the International Association for the Study of Lung Cancer (IASLC) has published an atlas to structure and illustrate PD-L1 IHC analysis. ${ }^{28}$ Only one study, published in 2020, has compared the use of QR1 with E1L3N, $22 \mathrm{C} 3$, and SP263 antibodies in lung cancer and shows no difference for routine analysis. ${ }^{29} \mathrm{We}$ used QR1 in practice for the evaluation of PD-L1 in lung cancer for several years, and offers good pricequality ratio. Finally, the IASLC indicated that E1L3N has the highest sensitivity for membranous expression when compared with SP142, 9A11, 015, and 7G11 which is why we chose this antibody in the current study. CPS in squamous cell carcinoma of the head and neck is approved by the FDA for the evaluation of PD-L1 (combined positive score $\geq 1$ ) to indicate treatment with pembrolizumab. ${ }^{30}$ However, for breast cancer, the FDA approves atezolizumab treatment when PD-L1 stained tumor-infiltrating immune cells of any intensity covers $\geq 1 \%$ of the tumor area using the SP142 clone. ${ }^{31}$ We chose to evaluate QR1 in this study because of data showing that the number of cDNAs (SC1, QR1, hevin) are similar to the secreted protein acidic and rich in cysteine (SPARC) protein, a matricellular protein that regulates cell adhesion, cell cycle, and matrix assembly and remodeling. ${ }^{32}$ Moreover, Tumbarello et al. demonstrated that SPARC regulates Transforming Growth Factor Beta Induced (TGFBI) extracellular matrix deposition and paclitaxel response in OC cells. ${ }^{33}$ Recently, John et al. found regulation of the bi-directional cross-talk between ovarian cancer cells and adipocytes by SPARC. ${ }^{34}$

Another finding of the present study is the relatively frequent expression of PD-L1 in CCC. Our results are in agreement with those of $\mathrm{Li}$ et al. reporting $21.1 \%$ of $\mathrm{CCC}$ positive for $\mathrm{PD}-$ L1(20/95) using both TMA with antibody PD-L1 clone SP263 and a semiquantitative immunoreactivity score. ${ }^{35} \mathrm{Zhu}$ et al. found PDL1 positivity in $48 \%$ of CCC (52/122) using a positivity threshold $\geq 10 \%$ (using an Abcam PD-L1 antibody).${ }^{19} \mathrm{~A}$ recent small series of 30 CCCs showed PD-L1 expression in tumor cells or immune cells (CPS equivalent score) in $44 \%$ of CCC with microsatellite stability (MSS) and in all cases of CCC with microsatellite instability (MSI) (3 cases). ${ }^{36}$ In addition, the expression of PD-L1 in HGSC appears to be linked to BRCA 1-2 mutations. ${ }^{37,38}$ Finally, several studies have underlined that $\mathrm{CCC}$ with MSI and HGSC with BRCA1-2 mutations overexpress PD-L1 with a high intratumoral infiltrate suggesting a potential increased sensitivity to PD-1/PDL1 inhibitors. ${ }^{37}$ In our series, patients with documented BRCA status, no significant association was found between the BRCA mutation and PD-L1 expression ( $\mathrm{p}=0.75)$.

From a clinical point of view, few targeted therapies are available in OC. Recently, anti-PARP has been shown to improve both RFS and OS of patients with somatic and germline BRCA 1-2. Matulonis et al.'s trial targeting OC with positive PD-L1 expression, reported objective response rates of $4.1 \%$ for CPS $<1,5.7 \%$ for $\mathrm{CPS} \geq 1$, and $10 \%$ for $\mathrm{CPS} \geq 10 .{ }^{39}$ Others recent studies suggested that the presence of $\mathrm{PD}-1 / \mathrm{PD}-\mathrm{L} 1$ positive tumor-infiltrating immune cells was a prognostic value in OC ${ }^{11}$. An original study suggested that higher PD-1 level in the plasma could be a predictive biomarker and predicted poor survival of OC patients. ${ }^{40}$ In addition, a recent study by Kim et al. showed that PD-L1 expression levels in tumor cells, intraepithelial tumor-infiltrating lymphocytes, and stromal tumor-infiltrating lymphocytes were correlated with a better prognosis in SC. ${ }^{41}$ Interestingly, our results showed a high PD-L1 expression in CCC, implying poor prognosis, supporting the analysis of PD-L1 expression in this specific histological subtype with a potential benefit of targeted therapy. However, PD-L1 expression is not always a marker of response. Xue et al., showed that addition of PARP inhibitor in vitro appears

\section{Global Population}
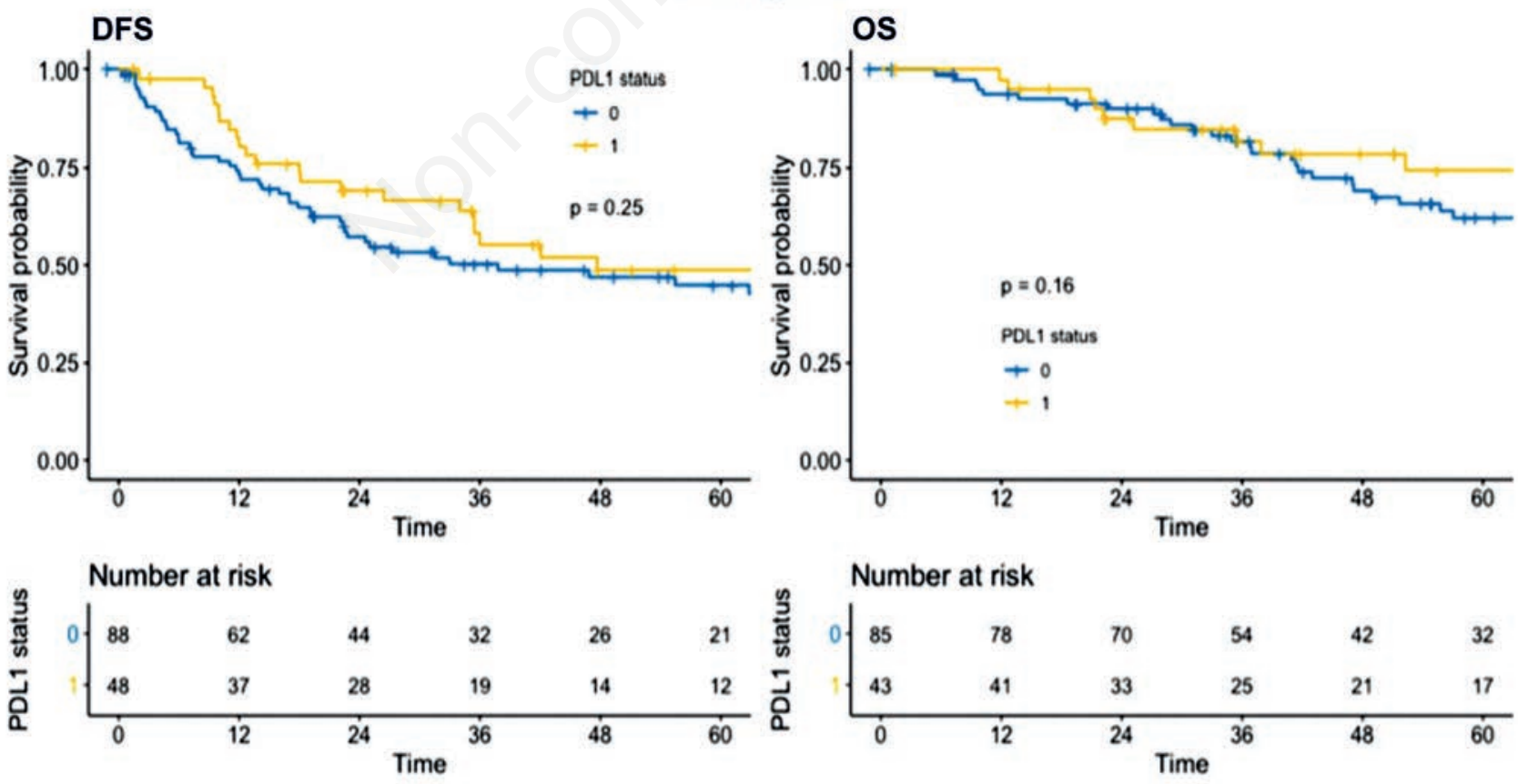

Number at risk

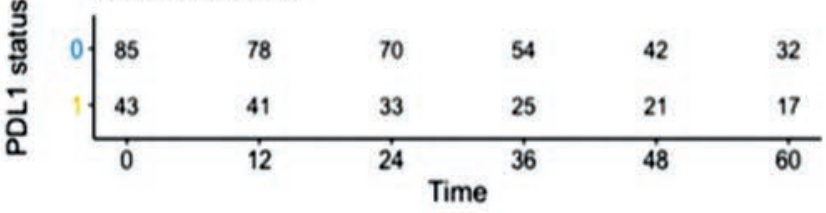

Figure 2. Progression-free survival (PFS) and overall survival (OS) of patients expressing PD-L1 (yellow line) and those with no PD-L1 expression (blue line). 
DFS and OS HGSC : Disease Free Survival and Overall survival High Grade Serous Carcinoma

DFS - HGSC

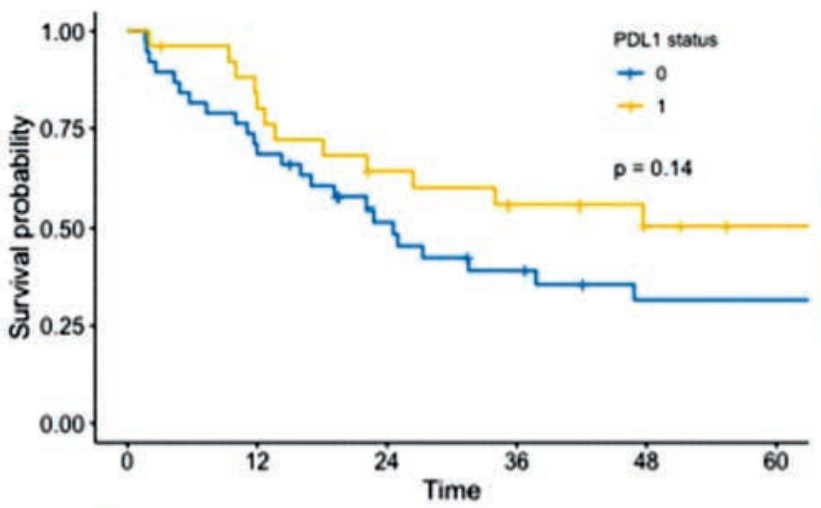

Number at risk

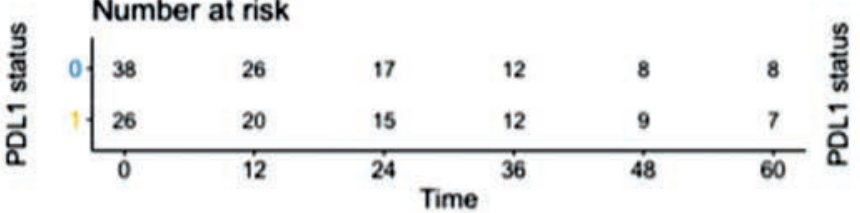

OS - HGSC

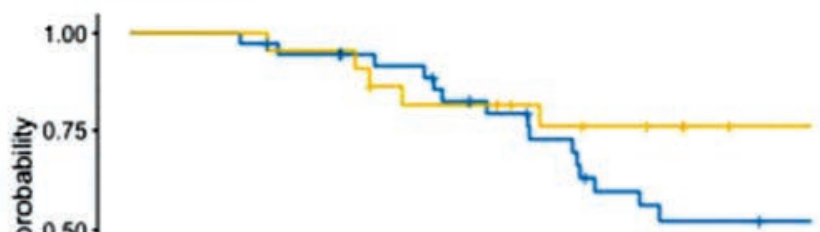

$p=0.19$

PDL1 status

$+0$

$+1$

\section{Number at risk}

\begin{tabular}{|c|c|c|c|c|c|}
\hline 37 & 36 & 31 & 25 & 16 & 14 \\
\hline 22 & 22 & 18 & 15 & 12 & 9 \\
\hline 0 & 12 & 24 & 36 & 48 & 60 \\
\hline
\end{tabular}

DFS and OS LGSC : Disease Free Survival and Overall survival Low Grade Serous Carcinoma

DFS - LGSC

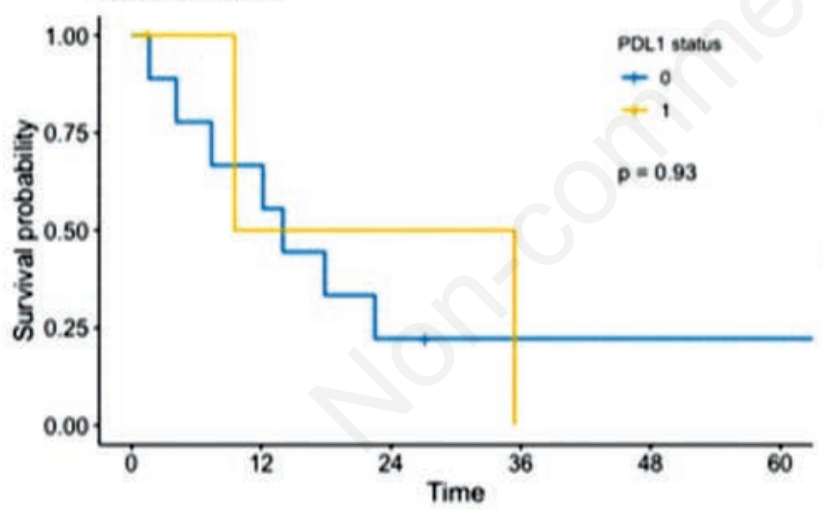

Number at risk

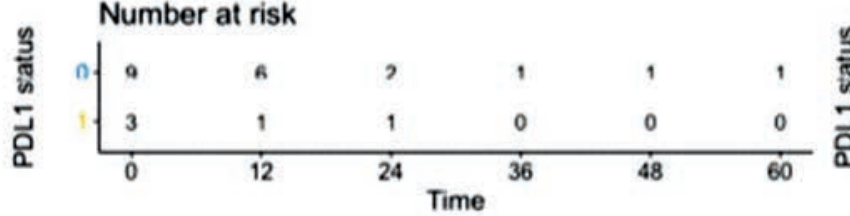

OS - LGSC

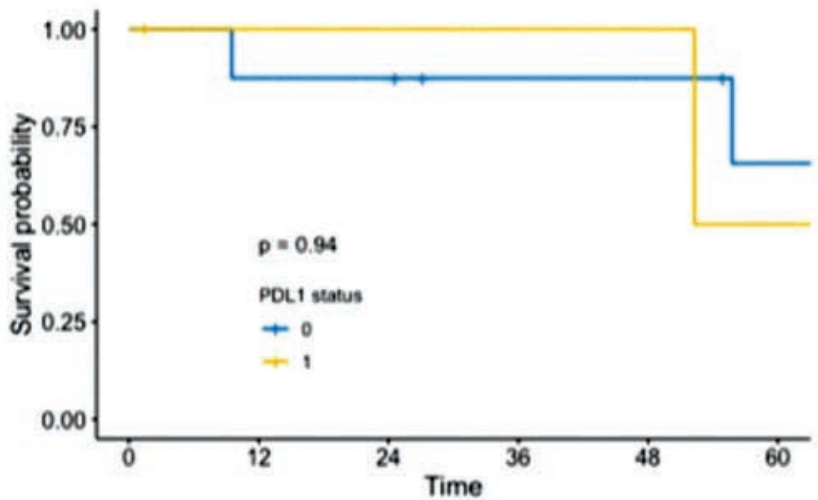

Number at risk

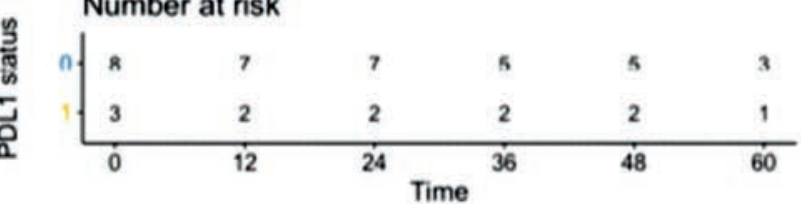

Figure 3. Disease-free survival (DFS) and overall survival (OS) of patients expressing PD-L1 (yellow line) and those with no PD-L1 expression (blue line), according to the histological type. 
to increase PD-L1 expression in OC cell lines through the Chk1 pathway. This information could suggest an interest in combining PD1/PD-L1 inhibitor and PARP inhibitor treatment. ${ }^{42}$

In breast cancer, it has been demonstrated that two-thirds of patients with PD-L1 positive tumors have a high response to targeted therapy but also $16.7 \%$ of PD-L1 negative patients. ${ }^{43}$ The ongoing "ATALANTE" trial is investigating the efficacy of atezolizumab compared to placebo in patients with PD-L1 positive OC compared to PD-L1 negative patients. Finally, other data found an increase in PD-L1 expression in the tumor or peritumoral stroma after neoadjuvant chemotherapy suggesting that anti-PD-L1 treatment might be administered in this specific setting. ${ }^{44}$ Some limits of the present study have to be underlined. First, we only evaluated two antibodies to analyze PD-L1 expression. However, both antibodies were selected based on data supporting their use in other cancers and on the pathogenesis of OC. Second, the low number of OCs expressing PD-L1 in our series might be a potential bias linked to the TMA method and heterogeneous tumor labeling as shown in Figure 1. However this method was validated by $\mathrm{Li}$ et al. for the evaluation of PD-L1 ${ }^{35}$ especially in CCC (showing $21 \%$ of positive cases). Third, we failed to determine a threshold for PD-L1 expression imposing further studies in large series. Fourth, no relation was evaluated between MSI and PD-L1. Finally, further analysis is required to evaluate the relation between PD-L1 expression and survival in OC especially for CCC.

To conclude, the present study shows that PD-L1 expression is relatively rare in OC with often less than $10 \%$ of tumor cells labeled. The QR1 clone and CPS appear to be the best tools to evaluate PD-L1 expression. Further studies are required to evaluate the impact of PD-L1 expression on the management of $\mathrm{OC}$ according to histologic subtype.

\section{References}

1 Coburn SB, Bray F, Sherman ME, Trabert B. International patterns and trends in ovarian cancer incidence, overall and by histologic subtype. Int J Cancer 2017;140:2451-60.

2 Institut National du Cancer. [Les cancers en France l'essentiel des faits et chiffres en 2017].[Report in French]. Available from: https://www.e-cancer.fr/Professionnels-de-sante/Leschiffres-du-cancer-en-France/Epidemiologie-descancers/Donnees-globales

3 Nasioudis D, Sisti G, Kanninen T, Holcomb K, Tommaso MD, Fambrini M, et al. Epidemiology and outcomes of squamous ovarian carcinoma; a population-based study. Gynecol Oncol 2016;141:128-33.

4 Sankaranarayanan R, Ferlay J. Worldwide burden of gynaecological cancer: the size of the problem. Best Pract Res Clin Obstet Gynaecol 2006;20:207-25.

5 Bell D, Berchuck A, Birrer M, Chien J, Cramer DW, Dao F, et al. Cancer Genome Atlas Research Network. Integrated genomic analyses of ovarian carcinoma. Nature 2011;474:60915.

6 Ventriglia J, Paciolla I, Pisano C, Cecere SC, Napoli MD, Tambaroet R, et al. Immunotherapy in ovarian, endometrial and cervical cancer: State of the art and future perspectives. Cancer Treat Rev 2017;59:109-16.

7 Nair D, Rådestad E, Khalkar P, Diaz-Argelich N, Schröder A, Klynning C, et al. Methylseleninic acid sensitizes ovarian cancer cells to T-cell mediated killing by decreasing PDL1 and VEGF Levels. Front Oncol 2018;8:407.

8 Dong H, Strome SE, Salomao DR, Tamura H, Hirano F, Flies DB, et al. Tumor associated B7-H1 promotes T-cell apoptosis: a potential mechanism of immune evasion. Nat Med
2002;8:793-800.

9 Dermani FK, Samadi P, Rahmani G, Kohlan AK, Najafi R. PD1/PD-L1 immune checkpoint: Potential target for cancer therapy. J Cell Physiol 2019;234:1313-25.

10 Wang Q, Lou W, Di W, Wu X. Prognostic value of tumor PDL1 expression combined with CD8+ tumor infiltrating lymphocytes in high grade serous ovarian cancer. Int Immunopharmacol 2017;52:7-14.

11 Buderath P, Mairinger F, Mairinger E, Böhm K, Mach P, Schmid KW, et al. Prognostic significance of PD-1 and PD-L1 positive tumor-infiltrating immune cells in ovarian carcinoma. Int J Gynecol Cancer 2019;29:1389-95.

12 Pujade-Lauraine E, Fujiwara K, Dychter SS, Devgan G, Monk BJ. Avelumab (anti-PD-L1) in platinum-resistant/refractory ovarian cancer: JAVELIN Ovarian 200 Phase III study design. Future Oncol 2018;14:2103-13.

13 Varga A, Piha-Paul S, Ott PA, Mehnert JM, Berton-Rigaud D, Morosky A, et al. Pembrolizumab in patients with programmed death ligand 1-positive advanced ovarian cancer: Analysis of KEYNOTE-028. Gynecol Oncol 2019;152:243-50.

14 Hamanishi J, Mandai M, Ikeda T, Minami M, Kawaguchi A, Murayama T, et al. Safety and antitumor activity of anti-PD-1 antibody, nivolumab, in patients with platinum-resistant ovarian cancer. J Clin Oncol 2015;33:4015-22.

15 Fan CA, Reader J, Roque DM. Review of immune therapies targeting ovarian cancer. Curr Treat Options Oncol 2018;19:74.

16 Wang L. Prognostic effect of programmed death-ligand 1 (PDL1) in ovarian cancer: a systematic review, meta-analysis and bioinformatics study. J Ovarian Res 2019;12:37.

17 Piao J, Lim HJ, Lee M. Prognostic value of programmed cell death ligand-1 expression in ovarian cancer: an updated metaanalysis. Obstet Gynecol Sci 2020;63:346-56.

18 Udall M, Rizzo M, Kenny J, Doherty J, Dahm SA, Robbins P, et al. PD-L1 diagnostic tests: a systematic literature review of scoring algorithms and test-validation metrics. Diagn Pathol 2018;13:12.

19 Zhu J, Wen H, Bi R, Wu Y, Wu X. Prognostic value of programmed death-ligand 1 (PD-L1) expression in ovarian clear cell carcinoma. J Gynecol Oncol 2017;28:e77.

20 Huang LJ, Deng XF, Chang F, Wu XL, Wu Y, Diao QZ. Prognostic significance of programmed cell death ligand 1 expression in patients with ovarian carcinoma: A systematic review and meta-analysis. Medicine (Baltimore) 2018;97:e12858.

21 Viera AJ, Garrett JM. Understanding interobserver agreement: the kappa statistic. Fam Med 2005;37:360-3.

22 Schmoeckel E, Hofmann S, Fromberger D, Rottmann M, Luthardt B, Burges A, et al. Comprehensive analysis of PD-L1 expression, HER2 amplification, ALK/EML4 fusion, and mismatch repair deficiency as putative predictive and prognostic factors in ovarian carcinoma. Virchows Arch. 2019;474:599608.

23 Büttner R, Gosney JR, Skov BG, Adam J, Motoi N, Bloom KJ, et al. Programmed death-ligand 1 immunohistochemistry testing: A review of analytical assays and clinical implementation in non-small-cell lung cancer. J Clin Oncol 2017;35:3867-76.

24 Adam J, Le Stang N, Rouquette I, Cazes A, Badoual C, PinotRoussel H, et al. Multicenter harmonization study for PD-L1 IHC testing in non-small-cell lung cancer. Ann Oncol 2018;29:953-8.

25 Qu QX, Xie F, Huang Q, Zhang XG. Membranous and cytoplasmic expression of PD-L1 in ovarian cancer cells. Cell Physiol Biochem 2017;43:1893-906.

26 Drakes ML, Mehrotra S, Aldulescu M, Potkul RK, Liu Y, 
Grisoli A, et al. Stratification of ovarian tumor pathology by expression of programmed cell death-1 (PD-1) and PD-ligand1 (PD-L1) in ovarian cancer J Ovarian Res 2018;11:43.

27 Koh J, Go H, Keam B, Kim MY, Nam SJ, Kim TM, et al. Clinicopathologic analysis of programmed cell death-1 and programmed cell death-ligand 1 and 2 expressions in pulmonary adenocarcinoma: comparison with histology and driver oncogenic alteration status. Mod Pathol 2015;28:1154-66.

28 Tsao MS, Kerr MK, Dacic S, Yatabe Y, Hirsch FR. IASLC atlas of PD-L1 immunohistochemistry testing in lung cancer. International Association for the Study of Lung Cancer. 2019.

29 Brandone N, Mascaux C, Caselles K, Rouquette I, Lantuejoul S, Garcia S. Validation of the QR1 antibody for the evaluation of PD-L1 expression in non-small cell lung adenocarcinomas. Appl Immunohistochem Mol Morphol 2020;28:23-9.

30 Cohen EEW, Bell RB, Bifulco CB, Burtness B, Gillison ML, Harrington KJ, et al. The Society for Immunotherapy of Cancer consensus statement on immunotherapy for the treatment of squamous cell carcinoma of the head and neck (HNSCC). J Immunother Cancer 2019;7:184.

31 Schmid P, Adams S, Rugo HS, Schneeweiss A, Barrios CH, Iwata $\mathrm{H}$, et al. Atezolizumab and nab-paclitaxel in advanced triple-negative breast cancer. N Engl J Med 2018;379:2108-21.

32 Soderling JA, Reed MJ, Corsa A, Sage EH. Cloning and expression of murine $\mathrm{SC} 1$, a gene product homologous to SPARC. J Histochem Cytochem 1997;45823-35.

33 Tumbarello DA, Andrews MR, Brenton JD. SPARC regulates transforming growth factor beta induced (TGFBI) extracellular matrix deposition and paclitaxel response in ovarian cancer cells. PLoS One 2016;11:e0162698.

34 John B, Naczki C, Patel C, Ghoneum A, Qasem S, Salih Z, et al. Regulation of the bi-directional cross-talk between ovarian cancer cells and adipocytes by SPARC. Oncogene 2019;38:4366-83.

35 Li M, Li H, Liu F, Bi R, Tu X, Chen L et al. Characterization of ovarian clear cell carcinoma using target drug-based molecular biomarkers: implications for personalized cancer therapy. J Ovarian Res 2017;10:9.

36 Xiao X, Dong D, He W, Song L, Wang Q, Yue J, et al.
Mismatch repair deficiency is associated with MSI phenotype, increased tumor-infiltrating lymphocytes and PD-L1 expression in immune cells in ovarian cancer. Gynecol Oncol 2018;149:146-54.

37 Zhu X, Zhao L, Lang J. The BRCA1 methylation and PD-11 expression in sporadic ovarian cancer. Int $\mathrm{J}$ Gynecol Cancer 2018;28:1514-9.

38 Strickland KC, Howitt BE, Shukla SA, Rodig S, Ritterhouse LL, Liu JF, et al. Association and prognostic significance of BRCA1/2-mutation status with neoantigen load, number of tumor-infiltrating lymphocytes and expression of PD-1/PD-L1 in high grade serous ovarian cancer. Oncotarget 2016;7:1358798.

39 Matulonis UA, Shapira-Frommer R, Santin AD, Lisyanskaya AS, Pignata S, Vergote I, et al. Antitumor activity and safety of pembrolizumab in patients with advanced recurrent ovarian cancer: Results from the phase 2 KEYNOTE-100 study. Ann Oncol 2019;30:1080-7.

40 Pawłowska A, Suszczyk D, Tarkowski R, Paduch R, Kotarski J, Wertel I. Programmed death-1 receptor (PD-1) as a potential prognosis biomarker for ovarian cancer patients. Cancer Manag Res 2020;12:9691-709.

41 Kim KH, Choi KU, Kim A, Lee SJ, Lee JH, Suh DS, et al. PDL1 expression on stromal tumor-infiltrating lymphocytes is a favorable prognostic factor in ovarian serous carcinoma. J Ovarian Res 2019;12:56.

42 Xue C, Xu Y, Ye W, Xie Q, Gao H, Xu B, et al. Expression of PD-L1 in ovarian cancer and its synergistic antitumor effect with PARP inhibitor. Gynecol Oncol 2020;157:222-33.

43 Dirix LY, Takacs I, Jerusalem G, Nikolinakos P, Arkenau HT, Forero-Torres A, et al. Avelumab, an anti-PD-L1 antibody, in patients with locally advanced or metastatic breast cancer: a phase 1b JAVELIN Solid Tumor study. Breast Cancer Res Treat 2018;167:671-86.

44 Mesnage SJL, Auguste A, Genestie C, Dunant A, Pain E, Drusch F, et al. Neoadjuvant chemotherapy (NACT) increases immune infiltration and programmed death-ligand 1 (PD-L1) expression in epithelial ovarian cancer (EOC). Ann Oncol 2017;28:651-7.

Received for publication: 30 September 2020. Accepted for publication: 10 February 2021.

This work is licensed under a Creative Commons Attribution-NonCommercial 4.0 International License (CC BY-NC 4.0).

(C) Copyright: the Author(s), 2021

Licensee PAGEPress, Italy

European Journal of Histochemistry 2021; 65:3185

doi:10.4081/ejh.2021.3185 